\title{
A temporal stability analysis of the Australian SMAP mission validation site
}

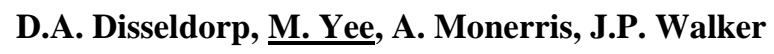 \\ Department of Civil Engineering, Monash University, Clayton, Australia \\ Email: \{mei.yee, sandra.monerris-belda, jeff.walker\}@monash.edu
}

\begin{abstract}
The National Aeronautics and Space Administration's (NASA) Soil Moisture Active Passive (SMAP) mission is a soil moisture dedicated mission scheduled for launch in October 2014. The payload consists of a combined L-band radar and radiometer system with the objective of mapping near surface soil moisture globally. The scientific rationale for SMAP is an improved accuracy and spatial resolution of the soil moisture estimates through a unique combination of high resolution $(3 \mathrm{~km})$ but noisy radar derived soil moisture information and more accurate yet lower resolution $(36 \mathrm{~km})$ radiometer derived soil moisture information, yielding a $9 \mathrm{~km}$ active/passive soil moisture product.
\end{abstract}

Soil moisture estimates from remote sensing data have an inherent uncertainty due to the model required to convert the observed microwave signal into area-average soil moisture. Validation of the satellite products is thus required after launch to ensure their accuracy. This can be difficult due to the high spatio-temporal variability of soil moisture and the mismatch in scale of point measurements and satellite footprints. One method of overcoming this problem is to use hydrological monitoring networks that have been collecting data over a long period, by finding point measurement locations that are representative of the area-average values. This technique is known as temporal stability analysis.

As part of the Australian contribution to the SMAP mission, a calibration/validation site has been developed at Yanco, New South Wales. The Yanco site is part of the OzNet soil moisture monitoring network and has been intensively monitored for remote sensing purposes since 2001 (www.oznet.org.au). This paper presents a temporal stability analysis using data from the Yanco site to assess the most suitable monitoring stations to be used as the test-bed for SMAP. The soil moisture stations are located in a specifically designed nested grid to assist with the validation of the $3 \mathrm{~km}, 9 \mathrm{~km}$ and $36 \mathrm{~km}$ SMAP soil moisture products. Results show that in the cropping area, YA4 and YA7 $(3 \mathrm{~km} \times 3 \mathrm{~km})$ are best represented by YA4b and YA7d stations, respectively. A high standard deviation in soil moisture is found in the YA $(9 \mathrm{~km} \times 9 \mathrm{~km})$ due irrigation and cropping practices. On the other hand, the grassland area YB7 $(3 \mathrm{~km} \times 3 \mathrm{~km})$ is well represented by the YB7d station, with the YB3 station giving a good approximation of the average soil moisture for the entire YB area $(9 \mathrm{~km} \times 9 \mathrm{~km})$ and the Y10 station a good approximation for the entire $36 \mathrm{~km} \times 36 \mathrm{~km}$ area.

A sensitivity analysis was then performed supporting the choice of the Y10 station and leading to the conclusion that approximately 1 year of data are required to determine the most representative station within a given area. Data from the Y10 station has been also compared to the average moisture from a number of OzNet monitoring stations and was found to provide an accurate estimate of their average value for soil moisture lower than $0.3 \mathrm{~m}^{3} / \mathrm{m}^{3}$.

Keywords: Temporal stability, soil moisture, OzNet, Soil Moisture Active Passive (SMAP), satellite validation, monitoring network. 


\section{INTRODUCTION}

Spatial and temporal variations of soil moisture have a vast impact on a range of hydrological, ecological, and biogeochemical process (Engman and Chauhan, 1995). Such data are essential for efficient irrigation scheduling and cropping practices, accurate initialisation of climate prediction models, and setting the correct antecedent moisture conditions in flood forecasting models (Walker, 1999). The fundamental limitation is that soil moisture is difficult to measure with a consistent and spatially comprehensive basis (Engman \& Chauhan, 1995), due to large spatial and temporal variability and the large cost associated with installing and operating intensive networks of soil moisture probes. Remote sensing provides an ideal tool to map soil moisture globally and with high temporal frequency, and microwave radiation has proved to be the most promising approach due to its all-weather capability and relationship with soil moisture through the soil dielectric constant. Whilst active (radar) microwave sensing at L-band $(\sim 1.4 \mathrm{GHz})$ has shown some positive results, passive (radiometer) microwave measurements at L-band are least affected by land surface roughness and vegetation cover, which allows observations of the underlying layers. Consequently, the European Space Agency (ESA) launched the Soil Moisture and Ocean Salinity (SMOS) mission in November 2009, being the first-ever dedicated soil moisture mission based on L-band passive microwave radiometry (Kerr et al., 2010). However, space-borne L-band radiometric data provides low spatial resolution measurements, on the order of $40 \mathrm{~km}$, which makes them appropriate for broad scale applications, but not useful for small scale applications such as on-farm water management, flood prediction, or meso-scale climate and weather prediction. To address the requirement for higher resolution soil moisture data, the National Aeronautics and Space Administration (NASA) proposed the Soil Moisture Active Passive (SMAP) mission. The basis for SMAP is that the high resolution $(3 \mathrm{~km})$ but noisy soil moisture data from the radar and the more accurate but low resolution $(36 \mathrm{~km})$ soil moisture data from the radiometer will be used synergistically to produce a high accuracy and improved spatial resolution $(9 \mathrm{~km})$ soil moisture product with high temporal frequency (Entekhabi et al., 2010).

Soil moisture estimates from remote sensing data have an inherent uncertainty, due to the model required to convert the remotely-sensed microwave signal into area-average soil moisture (Jupp et al., 1998). In order to ensure the accuracy of remotely sensed soil moisture products it is important that results are thoroughly validated after launch. This can be very difficult due to the high spatial variability in soil moisture, the 'mismatch' in scale of ground point measurements, and the very large satellite sensed footprint (Cosh et al., 2004). One method of overcoming this difficulty is to utilize hydrological monitoring networks that have been collecting data over a long period of time to find point measurements that are the closest representative of the area-average values. This is done using a technique known as temporal stability analysis. This method overcomes the issue of determining the temporal variation faced by other validation methods, such as comparison with high spatial resolution in-situ soil moisture sampling, because it allows comparison over a long period of time after launch instead of at limited points in time.

This paper will focus on the Yanco site within the Murrumbidgee river catchment, New South Wales, Australia, which has been intensively monitored for remote sensing purposes since 2001 (www.oznet.org.au; Smith et al., 2012). This site has been selected as a core site for the calibration/validation of the SMOS, SMAP, and GCOM-W1 missions and has also been the focus of field experiments dedicated to algorithm development studies for the SMOS and SMAP missions:

- National Airborne Field Experiment 2006 (NAFE'06; Merlin et al., 2009; www.nafe.unimelb.edu.au);

- Australian Airborne cal/val Experiments for SMOS (AACES-1,-2; Peischl et al., 2012; www.moisturemap.monash.edu.au/aaces);

- Soil Moisture Active Passive Experiments (SMAPEx-1,-2,-3; Panciera et al., 2013; www.smapex.monash.edu.au).

Data collected by stations from the OzNet monitoring network at Yanco have been used to assess the temporal stability and the feasibility of using the Yanco site for validation of SMAP soil moisture products at different spatial resolutions. In particular, the most representative stations for making an assessment of SMAP soil moisture products at $3 \mathrm{~km}, 9 \mathrm{~km}$ and $36 \mathrm{~km}$ spatial resolutions have been determined.

\section{DESCRIPTION OF THE SITE AND DATA SET}

The Yanco site is a $60 \mathrm{~km} \times 60 \mathrm{~km}$ area located in the flat western plains of the Murrumbidgee catchment, New South Wales, Australia. It is primarily used for rice and barley/corn crops in the west, dry land cropping in the north, and native pasture in the south east (Figure 1; Smith et al., 2012). The region has a mean annual rainfall of $394 \mathrm{~mm}$ with a relatively even spread across all months, whilst the mean maximum 


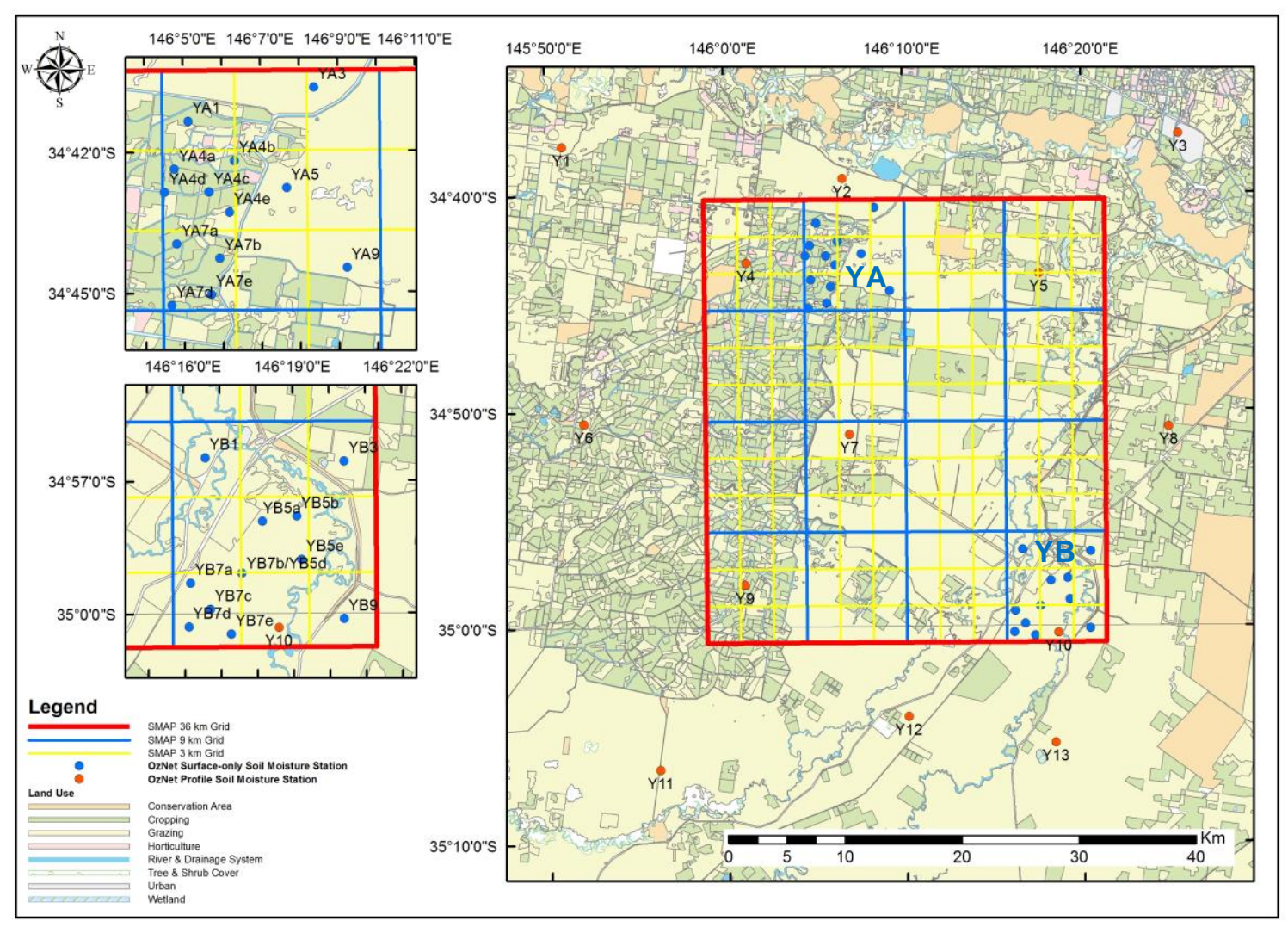

Figure 1. Overview of the OzNet soil moisture monitoring network and land use at the Yanco site. The SMAP grid at different spatial resolutions has been highlighted: $36 \mathrm{~km} \times 36 \mathrm{~km}$ radiometer pixel (red), $9 \mathrm{~km}$ $\times 9 \mathrm{~km}$ radar-radiometer pixel (blue) and $3 \mathrm{~km} \times 3 \mathrm{~km}$ radar pixel (yellow). (Insets) Detail of the YA and YB areas containing a cluster of surface-only soil moisture monitoring stations.

daily temperature varies greatly over the year with a mean of $33.9^{\circ} \mathrm{C}$ for January and a mean of $14.3^{\circ} \mathrm{C}$ for July (BOM, 2013). Soil moisture data in the area has been collected since 2001 as part of the OzNet hydrological monitoring network. There are 13 permanent stations spread throughout the Yanco region measuring the soil moisture profile from 0 to $90 \mathrm{~cm}$ (labeled $Y_{i}, i=1: 13$ ). In addition, two clusters comprising a total of 24 surface-only soil moisture stations $(0-5 \mathrm{~cm})$ were installed in 2009 in preparation of the SMAPEx field experiments (Figure 1; Smith et al., 2012, Panciera et al., 2013). These cluster stations have been placed within a grid to coincide with the $3 \mathrm{~km}, 9 \mathrm{~km}$ and $36 \mathrm{~km}$ SMAP pixels, making it an ideal arrangement for ground validation of the satellite products (see detailed location of the stations in Figure 1 (inset)). The two focus areas have been labeled as YA and YB, with YA in the north-west comprising mainly irrigated crops, and YB in the south-east comprising dry grassland. Thirteen out of the 24 surface-only stations are in YA while the other 11 stations are in YB, installed in such a way that at least 4 or 5 of them fall within two $3 \mathrm{~km} \times 3 \mathrm{~km}$ areas at both YA and YB. Note that all YB stations are installed in dry grassland while all YA stations are installed in different irrigated crops except YA3, YA4d, YA5 and YA9, which are in dry grassland. The data used in this paper corresponds to the top $(0-5 \mathrm{~cm})$ soil moisture values recorded by the $\mathrm{Y}_{i}$ stations since 2006, and the YA and YB stations since their installation in 2009. The data set is available through the OzNet website www.oznet.org.au.

\section{METHODOLOGY}

Temporal stability studies by Vachaud et al. (1985) noted that point measurements at some locations were representative of the area-average soil moisture. This is of particular interest for the validation of satellite products, in which different measurements at different spatial scales are involved. In order to find the representative site from a number of stations within an area, the mean relative difference is computed. This compares the point value at each station with respect to the area-average value of the whole monitoring network over an extensive period of time, and shows how well a given station represents the average. A station is considered to be representative of an area if it has a mean relative difference close to zero. In addition, the standard deviation of relative difference from the mean for each station is calculated, to 
determine how temporally stable the location is relative to the mean. A site with a mean relative difference of zero and a very low standard deviation will nearly always provides a value very close to the area-average soil moisture, whereas one with a mean relative difference of zero and a high standard deviation will vary significantly from the spatial mean depending on when the sample is taken.

\section{RESULTS AND DISCUSSION}

A major assumption associated with the use of temporal stability analysis for the validation of remotely sensed soil moisture is that the average of the soil moisture from all of the stations in an area is actually representative of its spatial mean. In a study not shown in this manuscript, soil moisture from the Yanco stations was compared to in-situ soil moisture samples collected in a $250 \mathrm{~m}$ grid during the SMAPEx campaigns in six different focus areas (see further information in Panciera et al., 2013). Data from the stations varies from $0.19 \mathrm{~m}^{3} / \mathrm{m}^{3}$ below the $3 \mathrm{~km} \times 3 \mathrm{~km}$ area-average of the intensive sampling within $1 \mathrm{~km}$ from the station, to $0.06 \mathrm{~m}^{3} / \mathrm{m}^{3}$ above it. Moreover, data from the stations consistently underestimated the area-average during SMAPEx-1 and -2 campaigns (wet soil) while it showed a relatively unbiased estimate of the area-average during SMAPEx-3 (dry soil). A conclusion from this analysis is that temporal stability analysis should not be relied upon solely to provide an accurate spatial mean estimate for validation purposes, particularly during wet periods. Instead it should be used in combination with a number of other methods to reduce the uncertainties associated and ensure more accurate validation.

To find the most representative stations at each of the SMAP pixels ( $3 \mathrm{~km}, 9 \mathrm{~km}$ and $36 \mathrm{~km}$ ), and assist in the post-launch validation, temporal stability analysis was performed on soil moisture data from: (i) four $3 \mathrm{~km} \times$ $3 \mathrm{~km}$ focus footprints (YA4, YA7, YB5 and YB7); (ii) two $9 \mathrm{~km} \times 9 \mathrm{~km}$ focus footprints (YA and YB); and (iii) the $36 \mathrm{~km} \times 36 \mathrm{~km}$ footprint (see Figure 1). The study was performed in this order so that only the most representative station from each $3 \mathrm{~km}$ area was used to represent its respective area at the $9 \mathrm{~km}$ scale, and only the most representative station from $9 \mathrm{~km}$ footprints was used to represent these areas in the $36 \mathrm{~km}$ scale. This ensures that the spatial average would not be biased towards the moisture conditions in those areas having a larger number of soil moisture stations. The temporal stability analysis considers all days in which data were available for at least $75 \%$ of the stations.

\subsection{The $3 \mathrm{~km} \times 3 \mathrm{~km}$ areas}

Temporal stability analysis was performed on four $3 \mathrm{~km} \times 3 \mathrm{~km}$ areas containing larger number stations, namely YA4, YA7, YB5 and YB7. At each of the areas, the stations were ranked in order from the lowest to the highest mean relative difference. Results are shown in Figure 2. As can be seen, YA4b is the station with the smallest mean relative difference in YA4, with a mean relative difference (in units of volumetric soil moisture) of $9.6 \%$ above the area-average soil moisture and a standard deviation of $35 \%$. The high standard deviation, however, indicates that YA4b does not provide a temporally stable or accurate estimate and thus will likely have limited value when validating the $3 \mathrm{~km}$ SMAP product. YA7d is the most representative station in the YA7 area, with a mean relative difference of $6.4 \%$ and standard deviation of $36.1 \%$. Again the associated high standard deviation is deemed to limit the value of this station for small scale footprint validation. The high standard deviation in both YA areas can be attributed to the large variation amongst

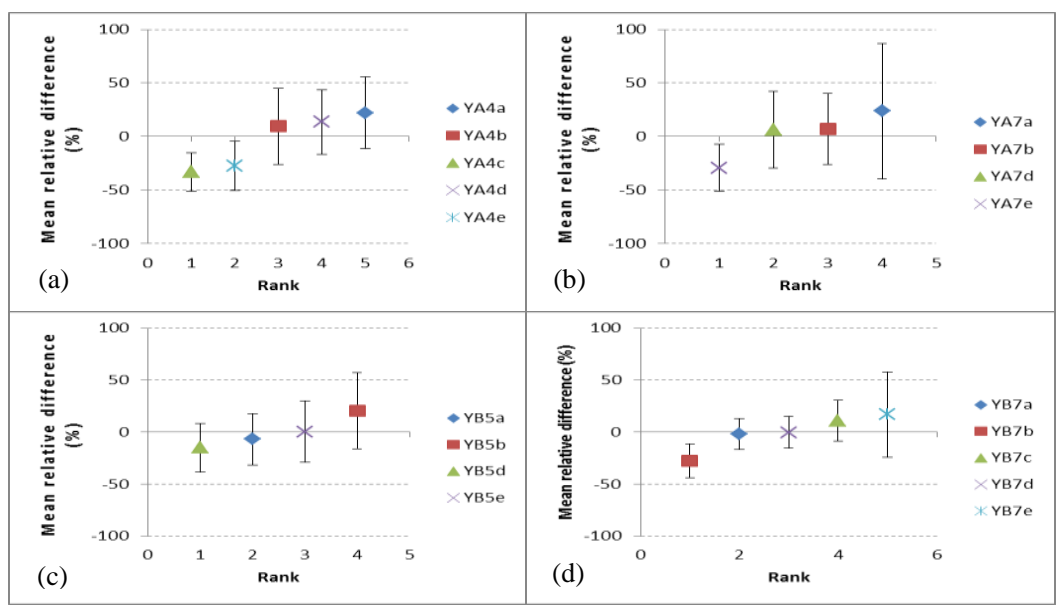

Figure 2. Mean relative difference for (a) YA4, (b) YA7, (c) YB5 and (d) YB7. 


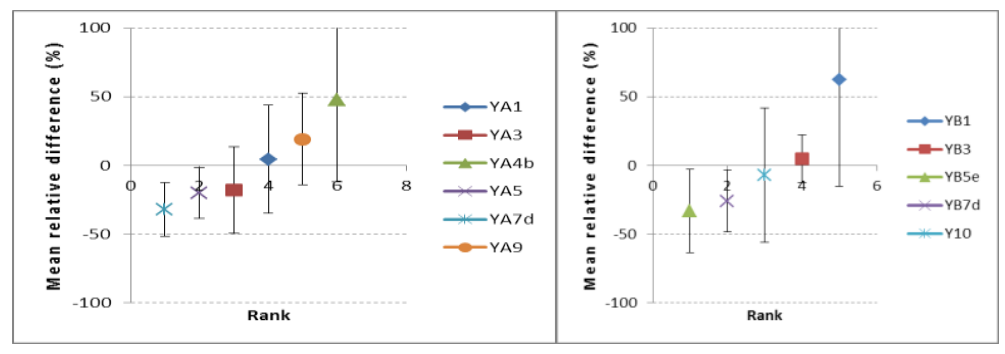

Figure 3. Mean relative difference for (left) YA and (right) YB areas.

stations as a result of irrigation and cropping practices. In the grassland region, YB5e is the most representative station within the YB5 area with a mean relative difference of $0.5 \%$ and standard deviation of $29.2 \%$. Whilst this is an improvement on the YA stations, again the station is not temporally stable with regards to the area-average. YB7d is the most representative station of the YB7 area, with a mean relative difference of $-0.25 \%$ and a standard deviation of $15.4 \%$. These values indicate that the station estimates the mean with $\pm 15 \%$ for approximately two thirds of the time window considered, making this station a candidate reference for SMAP validation purposes.

\subsection{The $9 \mathrm{~km} \times 9 \mathrm{~km}$ areas}

Temporal stability analysis was performed on the two $9 \mathrm{~km} \times 9 \mathrm{~km}$ focus areas (YA and YB) with the resulting mean relative difference plots shown in Figure 3. YA1 is the most representative station in YA, with a mean relative difference of $4.5 \%$ above the spatial average and a standard deviation of $39 \%$, meaning there are large variations between the station and the spatial mean depending on the day of measurement. This can again be largely explained by the irrigation practices in the region. Station YB3 is the most representative for $\mathrm{YB}$, with a standard deviation of $17.4 \%$, and thus could potentially assist in the validation of the SMAP $9 \mathrm{~km}$ resolution product. Since the large standard deviation associated with station Y10 can be largely attributed to large data gaps, Y10 data were split into periods: (i) before summer 2010, where it underestimates the mean (mean relative difference of -42\%) and (ii) after summer 2010, where it overestimates the mean (mean relative difference of 24\%), giving the false impression that the site is temporally unstable relative to the spatial mean. None of the most representative stations identified for the 3 $\mathrm{km}$ scale are found to be representative when evaluating the larger $9 \mathrm{~km}$ pixel. Moreover, none of these stations were even close to having a mean relative difference of zero, though standard deviations were generally relatively low. This supports reasoning that soil moisture is highly spatially variable, as locations representative of an area are not necessarily good indicators of the average soil moisture when compared over a larger area.

\subsection{The $36 \mathrm{~km} \times 36 \mathrm{~km}$ area}

The mean relative difference plot shown in Figure 4 (top) shows results using data from the stations spread across the entire $36 \mathrm{~km}$ footprint from summer 2009 until the end of autumn 2011. The most representative station of both focus areas would have been used for the analysis, however there was a significant amount of data missing from YB3 for this analysis period and so the decision was made to use Y10 (second most representative station in YB) in its place. Station Y10 was found to be the most representative station of the entire grid area, with relative mean difference and standard deviation of $-6.9 \%$ and $18 \%$ respectively. This result asserts Y10 as being in a location representative of the average soil moisture over this larger area. It was also noted that the standard deviation is much less at this site when considering analysis over the entire grid, than when only the YB focus area is analysed. This indicates that Y10 was heavily impacted by YB1 when analysing the YB focus area to be convinced of its seemingly temporally unstable characteristics.

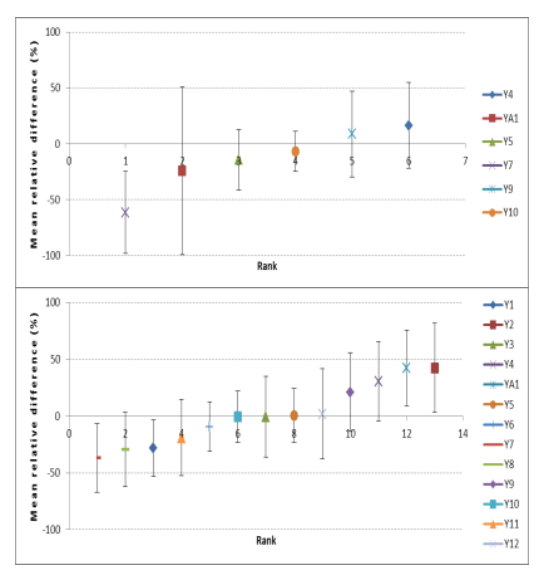

Figure 4. Mean relative difference plot for (top) stations strictly within the 36 $\mathrm{km} \times 36 \mathrm{~km}$ grid and (bottom) the entire Yanco site. 


\subsection{Sensitivity Analysis}

In order to test the robustness of the $36 \mathrm{~km}$ scale results, the analysis was repeated with the inclusion of all the Yanco stations (Figure 1), even those not strictly within the $36 \mathrm{~km}$ footprint (ie. Y1, Y3, Y6, Y8, Y11 and Y12). Figure 4 (bottom) shows that $\mathrm{Y} 10$ is again the most representative of the area-average soil moisture, even when additional stations are considered. In fact, for this case, it had a mean relative difference even closer to zero $(0.6 \%)$, whilst the standard deviation remained similar $(22.4 \%)$. It is thus concluded that Y10 provides a good estimate of the mean soil moisture over the SMAP radiometer pixel, making the station well suited for validation purposes.

To investigate the impact of time window considered on the temporal stability analysis, three different time frames were analysed for all Y stations: 1/12/2006 to 30/11/2007, to $30 / 11 / 2008$, and to $30 / 11 / 2010$. Results are presented in Figure 6. Mean relative difference plots show that there are only very small changes between a temporal stability analysis of 1 to that of 2 or 4 years. These results agree with those in Martínez-Fernández and Ceballos (2005), which after studying a small and a large catchment in the River Duero basin, Spain, determined that the minimum time to choose a representative station of an area was approximately 1 year.

\subsection{Towards satellite validation}

Figure 5 shows a time series of the average daily soil moisture for all stations within the $36 \mathrm{~km}$ Yanco area. The average across all stations has also been plotted to allow a comparison between this average and that from the most representative station (Y10). Results enhance the fact that Y10 provides a very good estimate of the area-average soil moisture. During wet periods however, when soil moisture is in the order of $0.3 \mathrm{~m}^{3} / \mathrm{m}^{3}, \mathrm{Y} 10$ tends to overestimate the mean soil moisture at the $36 \mathrm{~km}$ scale.

\section{CONCLUSIONS}

The results obtained in this work show that whilst there are uncertainties, and despite (i) the assumption that the average across a number of stations within an area is equal to the areal mean soil moisture, and (ii) the temporal instability in most focus footprints as indicated by the high standard deviation (particularly due to irrigation practices), it was still possible to provide a reasonable estimate of the area-average soil moisture in many cases. The best station for validation of SMAP was found to be the YB7d for the $3 \mathrm{~km}$ product, YB3

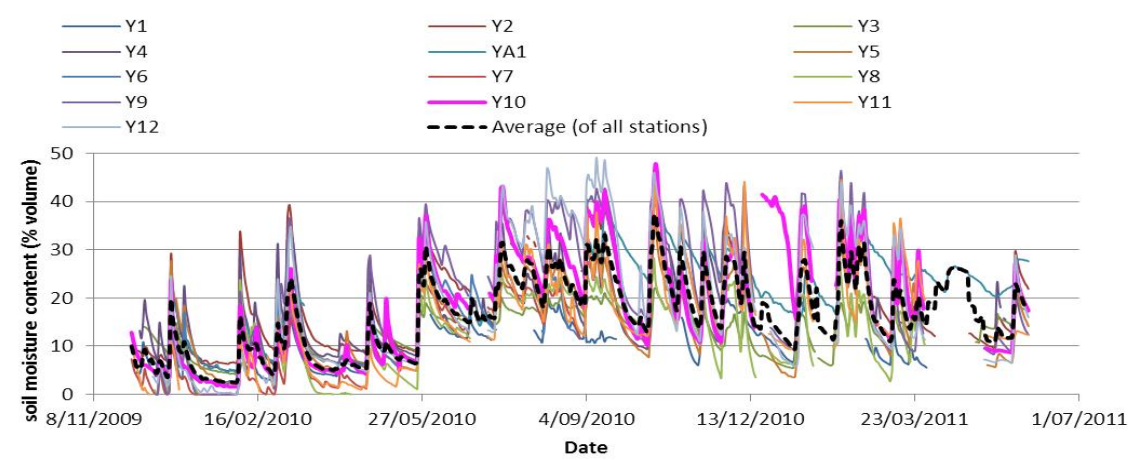

Figure 5. Time series of daily average soil moisture at different stations within the $36 \mathrm{~km} \times 36 \mathrm{~km}$ area from Dec 2009 to May 2011 . 
for the $9 \mathrm{~km}$ product and Y10 for the $36 \mathrm{~km}$ product. Approximately 1 year of data was found to be sufficient to determine the most representative station of an area, and therefore recommended the soil moisture network stations that are the most representative.

\section{ACKNOWLEDGMENTS}

OzNet has been funded by the Cooperative Research Centre for Catchment Hydrology and Australian Research Council (ARC) Discovery Grants DP0343778, DP0557543, and DP0879212. Installation of the semi-permanent SMAPEx stations was funded by ARC Discovery Grant DP0984586.

\section{REFERENCES}

Bureau of Meteorology (2013). Summary statistics of the Yanco Agricultural Institute. http://www.bom.gov.au/climate/averages/tables/cw_074037.shtml [Accessed 26 May 2013].

Cosh, M. H., Jackson, T. J., Bindlish, R. and Prueger, J. H. (2004). Watershed scale temporal and spatial stability of soil moisture and its role in validating satellite estimates. Remote Sensing of Environment, 92(4), 427-435.

Engman, E. T. and Chauhan, N. (1995). Status of microwave soil moisture measurements with remote sensing. Remote Sensing of Environment, 51(1), 189-198.

Entekhabi, D., Njoku, E.G., O'Neill, P.E et al. (2010) The Soil Moisture Active Passive (SMAP) Mission. Proc. IEEE, 98, 704-716.

Jupp, D.L.B., Guoliang, T., McVicar, T.R., Yi, Q. and Fuqinet, L. (1998) Soil moisture and drought monitoring using remote sensing I: Theoretical background and methods. CSIRO - Office of Space Science \& Applications/Earth Observation Centre - Crops and climate, 96 pages.

Kerr, Y.H., Waldteufel, P., Wigneron, J.-P. et al. (2010) The SMOS mission: New tool for monitoring key elements of the global water cycle. Proc. IEEE, 98(5), 666-687.

Martínez-Fernández, J. and Ceballos, A. (2005) Mean soil moisture estimation using temporal stability analysis. Journal of Hydrology, 312(1-4), 28-38.

Merlin, O., Walker, J.P., Panciera, R., Escorihuela, M.-J., Jackson, T.J. (2009) Assessing the SMOS soil moisture retrieval parameters with high-resolution NAFE'06 data. IEEE Geoscience and Remote Sensing Letters, 6(4), 635-639.

Panciera, R., Walker, J.P., Jackson, T.J., Gray, D., Tanase, M.A., Ryu, D., Monerris, A., Yardley, H., Rüdiger, C., Wu, X., Gao, Y. and Hacker, J. (2013) The Soil Moisture Active Passive Experiments (SMAPEx): Towards soil moisture retrieval from the SMAP mission. IEEE Transactions on Geoscience and Remote Sensing, PP(99), 1-18, doi: 10.1109/TGRS.2013.2241774.

Peischl, S., Walker, J. P., Rüdiger, C., Ye, N., Kerr, Y. H., Kim, E., Bandara, R. and Allahmoradi, M. (2012) The AACES field experiments: SMOS calibration and validation across the Murrumbidgee River catchment. Hydrology and Earth System Sciences, 16, 1697-1708.

Smith, A. B., Walker, J. P., Western, A. W., Young, R. I., Ellett, K. M., Pipunic, R. C., Grayson, R. B., Siriwidena, L., Chiew, F. H. S. and Richter, H. (2012) The Murrumbidgee soil moisture monitoring network data set. Water Resources Research, 48, W07701.

Vachaud, G., Passerat De Silans, A., Balabanis, P. and Vauclin, M. (1985) Temporal stability of spatially measured soil water probability density function. Soil Science Society of America Journal, 49(4), 822-828.

Walker, J.P. (1999) Estimating soil moisture profile dynamics from near-surface soil moisture measurements and standard meteorological data. PhD Thesis Dissertation, The University of Newcastle. 